\title{
Cell-type specific light-mediated transcript regulation in the multicellular alga Volvox carteri
}

\author{
Arash Kianianmomeni
}

\begin{abstract}
Background: The multicellular green alga Volvox carteri makes use of none less than 13 photoreceptors, which are mostly expressed in a cell-type specific manner. This gives reason to believe that trasncriptome pattern of each cell type could change differentially in response to environmental light. Here, the cell-type specific changes of various transcripts from different pathways in response to blue, red and far-red light were analyzed.

Results: In response to different light qualities, distinct changes in transcript accumulation of genes encoding proteins involved in chlorophyll and carotenoid biosynthesis, light-harvesting complexes, circadian clock and cell cycle control were observed. Namely, blue light tends to be effective to accumulate transcripts in the somatic cells; while red light leads to accumulate transcripts predominantly in the reproductive cells. Blue light also induced marked accumulation of two components of circadian rhythms only in the somatic cells, indicating that these clock-relevant components are affected by blue light in a cell-type specific manner. Further, we show that photosynthetic associated genes are regulated distinctly among cell types by different light qualities.

Conclusion: Our results suggest that Volvox uses different sophisticated cell-type specific light signaling pathways to modulate expression of genes involved in various cellular and metabolic pathways including circadian rhythms and photosynthesis in response to environmental light.
\end{abstract}

Keywords: Cell types, Light quality, Gene expression, Photoreceptors, Green algae

\section{Background}

The photosynthetic organisms such as free swimming microalgae use light signals to modulate a wide variety of physiological and cellular responses including sexual life cycle, circadian clock, cellular differentiation, cell cycle, nitrogen and lipid metabolism [1-4]. A sophisticated light-sensing system including various photoreceptors has been developed during evolution to monitor changes in the ambient light environment (quality, quantity, direction and duration) towards adjust growth and development (reviewed in [5-7]). Perception of light by -some of- photoreceptors activates signal transduction cascades which lead to regulate gene expression patterns during development or in response to different light signals $[8,9]$. These light-induced signal transduction pathways orchestrate the expression of downstream genes responsible for various physiological processes including circadian clock, chlorophyll and carotenoid biosynthesis $[10,11]$.

Correspondence: kianian@uni-bielefeld.de

Department of Cellular and Developmental Biology of Plants, University of Bielefeld, Universitätsstr. 25, D-33615 Bielefeld, Germany
Four major types of photoreceptors, i.e., phototropins, cryptochromes, rhodopsisns and UV-B photoreceptors, have been identified so far in the genome of volvocine algae, a group of chlorophytes including unicellular Chlamydomonas reinhardtii (hereafter Chlamydomonas) and multicellular Volvox carteri (hereafter Volvox) (reviewed in [6]). Although in vivo functions of some of these photoreceptors have been investigated in some detail in the unicellular Chlamydomonas [3,10,12-14], little is known about the molecular background of light reception mechanisms in the multicellular Volvox. However, the confusing maze behind individual activities of photoreceptors in the multicellular Volvox could contribute to understand the link between light and complex light-affected developmental processes such as cellular differentiation [2], which have been required for the evolutionary transition from unicellular organisms into a multicellular one $[15,16]$. Volvox is one of the simplest multicellular organisms composed of only two cell types, 2000-4000 biflagellate motile, terminally differentiated somatic cells, which build a monolayer at the surface of a spheroid, and around 16 
much larger immotile reproductive cells (so-called gonidia), which lie just below the somatic cell sheet; the cells are embedded in a transparent sphere of glycoproteinrich, extracellular matrix (ECM) (Figure 1) [17,18].

We recently have shown that Volvox photoreceptors are expressed in a cell-type-specific manner. Eight photoreceptors, i.e., a phototropin, a plant-like cryptochrome, channelrhodopsin-1 and -2 and four histidine kinase rhodopsins, highly express in the somatic cells $[6,16,19]$, while only one photoreceptor, i.e. volvoxopsin-1, has been found to predominantly express in the reproductive cells $[16,20]$ (Figure 1). These evidences strongly suggest that distinct cell type-specific light signaling pathways orchestrate gene expression in each cell type. Here, we investigated the cell type-specific changes in transcript accumulation of genes involved in downstream light signaling pathways. First, a diversified set of genes encoding components of light-harvesting system, carotenoid biosynthesis, tetrapyrrole biosynthesis, nitrogen metabolism, circadian clock and cell cycle were selected (Table 1). Further, we examined the lightresponsive expression of these genes in each cell types after exposure to blue, red and far-red lights. The results showed that the changes in transcript level underlined distinct light signaling pathways in each cell type. Moreover, we found that some of the selected genes become rapidly upregulated after the somatic cells were exposed to blue light, whereas the same genes were induced by red light in the reproductive cells. Our results show that different light qualities lead to cell-type specific expression or repression of genes, indicating the existence of different cell type specific light signaling pathways required for physiological and developmental adaptation to environmental light.

\section{Methods}

\section{Strain and culture conditions}

Cultures of Volvox carteri f. nagariensis female strain Eve10 [41] were maintained in standard Volvox medium [42] at $28^{\circ} \mathrm{C}$ in a cycle of $8 \mathrm{~h}$ dark $/ 16 \mathrm{~h}$ cool fluorescent white light at an average of $\sim 100 \mu \mathrm{mol}$ photons $\mathrm{m}^{-2} \mathrm{~s}^{-1}$ photosynthetically-active radiation (PAR). The reproductive and somatic cells were separated three hours before initiation of cleavage division (Additional file 1: Figure S1A) using Dounce homogenizer as described previously [37].

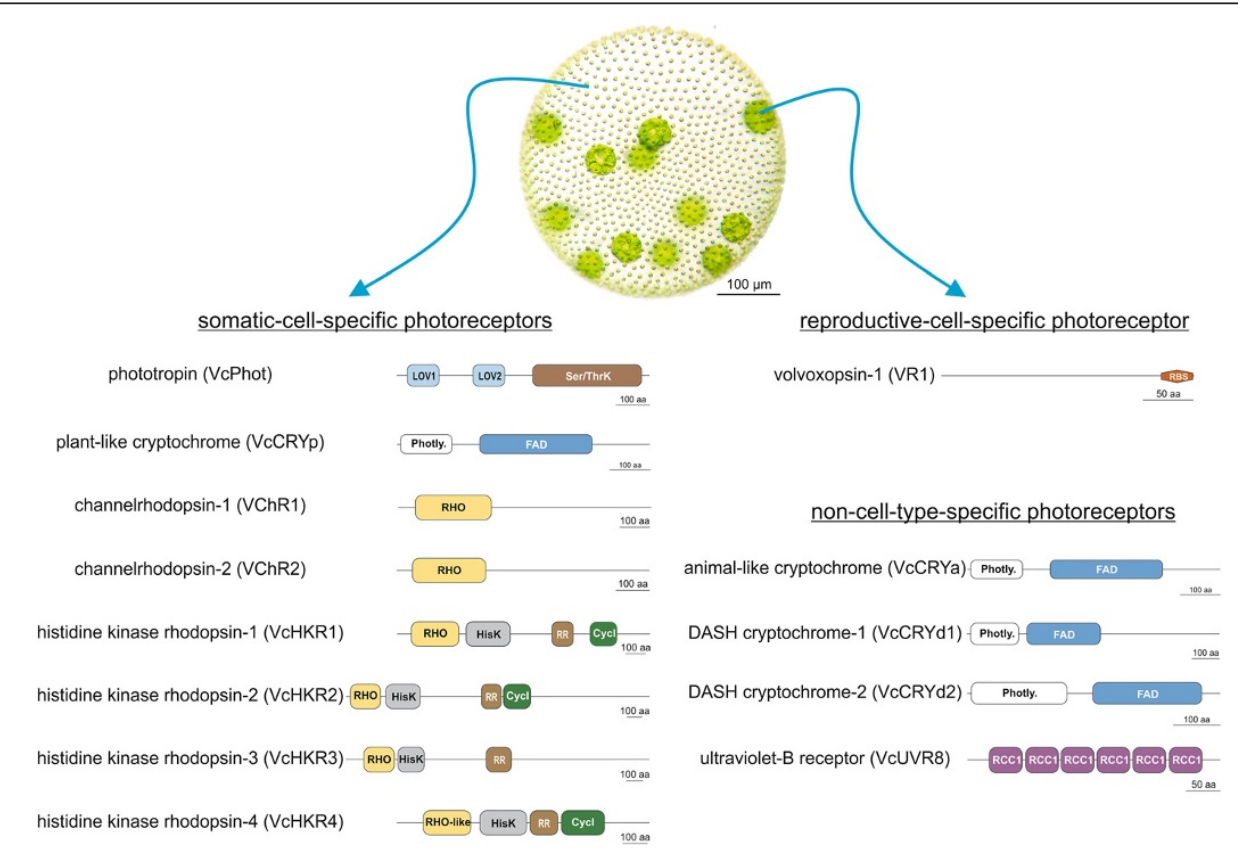

Figure 1 Volvox photoreceptors. Photograph of multicellualr Volvox and domain composition of its photoreceptors according to the Pfam database. Two different cell types, i.e., large dark green reproductive cells and small pale biflagellate somatic cells are located below and at the surface, respectively. Photoreceptors are categorized in three groups, i.e., somatic-, reproductive- and non-cell-specific photoreceptors, on the basis of their cell-type specific transcript levels (Additional file 2: Figure S2 and Additional file 4: Figure S3). Proteins are drawn approximately to scale. Domain abbreviations are photly. (photolyase domain), FAD (flavin adenine dinucleotide binding domain), LOV (Light-oxygen-voltage), Ser/ThrK (serine/threonine kinase), RBS (retinal binding site), RHO (rhodopsin), Hisk (histidine kinase), RR (response regulator), Cycl (adenylate/ guanylate cyclase domain), RCC1 (regulator of chromosome condensation). 


\begin{tabular}{|c|c|c|c|c|c|}
\hline Gene & Description/Function & $\begin{array}{l}\text { Accession Number/ } \\
\text { Reference }\end{array}$ & $\begin{array}{l}\text { Percentage of sequence } \\
\text { identity to the homologous } \\
\text { protein from the closely } \\
\text { related alga Chlamydomonas }\end{array}$ & $\begin{array}{l}\text { Accession number of used } \\
\text { homolog for sequence } \\
\text { comparison/Reference }\end{array}$ & $\begin{array}{l}\text { Changes in transcript in } \\
\text { response to light/References }\end{array}$ \\
\hline LHCBM6 & $\begin{array}{l}\text { Chloropyll a-b binding protein of LHCII } \\
\text { type I/a major LHCII polypeptide } \\
\text { present in the trimeric antenna } \\
\text { complexes of PS II }\end{array}$ & XM_002959515/[21] & 93.3\% identity in 253 aa overlap & EDP01611/[22] & Blue, red and far-red light/[10,11,23] \\
\hline LHL4 & $\begin{array}{l}\text { Lhc-like protein Lhl4/distant relative of } \\
\text { light-harvesting Chla/b protein }\end{array}$ & XP_002956040/[21] & $64.1 \%$ identity in 284 aa overlap & BAD67138/[24] & Blue, green and red light/[25] \\
\hline CHLD & $\begin{array}{l}\text { Magnesium chelatase subunit D, } \\
\text { chloroplast precursor/involved in } \\
\text { chlorophyll biosynthesis }\end{array}$ & XP_002956151/[21] & 93.3\% identity in 704 aa overlap & EDP07156/[22] & White, blue and red light/[10,26] \\
\hline GSA & $\begin{array}{l}\text { Glutamate-1-semialdehyde 2,1- } \\
\text { aminomutase/key enzyme for } \\
\text { chlorophyll synthesis }\end{array}$ & XP_002950034/[21] & $92.2 \%$ identity in 464 aa overlap & Q39566/[27] & Blue, red and far-red light/[10,11,28] \\
\hline$P O R$ & $\begin{array}{l}\text { Protochlorophyllide reductase/involved } \\
\text { in protochlorophyllide and chlorophyll } \\
\text { biosynthesis }\end{array}$ & XP_002950278/[21] & $81.1 \%$ identity in 392 aa overlap & Q39617/[29] & Blue and red light/[10] \\
\hline$A L A D$ & $\begin{array}{l}\text { Delta-aminolevulinic acid dehydratase/ } \\
\text { key enzyme required for early steps in } \\
\text { chlorophyll biosynthesis }\end{array}$ & XP_002946379/[21] & 91\% identity in 388 aa overlap & Q42682/[30] & White, blue and green light/[11,28] \\
\hline OEE & $\begin{array}{l}\text { Oxygen evolving enhancer protein 1/ } \\
\text { part of the oxygen evolving complex of } \\
\text { photosystem II }\end{array}$ & XP_002954867/[21] & 87\% identity in 291 aa overlap & P12853/[31] & White light/[11] \\
\hline RB60 & $\begin{array}{l}\text { Disulfide isomerase } \mathrm{RB} 60 / \text { part of a } \\
\text { complex that regulates the translation } \\
\text { of the chloroplast-encoded } p s b A\end{array}$ & EFJ41881/[21] & $71 \%$ identity in 532 aa overlap & AAC49896/[32] & White and red light/[33] \\
\hline RB38 & $\begin{array}{l}\text { RNA-binding protein RB38/part of a } \\
\text { complex that regulates the translation } \\
\text { of the chloroplast-encoded } p s b A\end{array}$ & XP_002953456/[21] & $53.4 \%$ identity in 371 aa overlap & AAM76787/[34] & White, blue and red/[33] \\
\hline PDS & $\begin{array}{l}\text { Phytoene desaturase/key enzyme for } \\
\text { carotenoids synthesis }\end{array}$ & XP_002948155/[21] & 85.3\% identity in 572 aa overlap & EDP05305/[22] & Blue and red light/[10,11,35] \\
\hline PSY & $\begin{array}{l}\text { Phytoene synthase/key enzyme } \\
\text { involved in the first step of the } \\
\text { carotenoids biosynthetic pathway }\end{array}$ & XP_002956783/[21] & $86.3 \%$ identity in 379 aa overlap & EDO97702/[22] & White and blue light/[11,35,36] \\
\hline$C D K B 1$ & $\begin{array}{l}\text { Plant specific cyclin dependent } \\
\text { kinase/involved in the regulation } \\
\text { of the cell cycle }\end{array}$ & XP_002947156/[21] & $95.7 \%$ identity in 322 aa overlap & ED097594/[22] & Blue and red light/[10] \\
\hline CRB1 & $\begin{array}{l}\text { C1 subunit of the circadian RNA- } \\
\text { binding protein CHLAMY1/associated } \\
\text { with the circadian clock }\end{array}$ & XP_002957962/[21] & $57.9 \%$ identity in 482 aa overlap & EDP08399/[22] & Blue and red light/[10] \\
\hline
\end{tabular}


Table 1 Candidate genes chosen for analysis of cell-type specific change of transcript accumulation under blue, red and far-red light in Volvox (Continued)

\begin{tabular}{|c|c|c|c|c|c|}
\hline CRB3 & $\begin{array}{l}\text { C3 subunit of the circadian RNA- } \\
\text { binding protein CHLAMY1/associated } \\
\text { with the circadian clock }\end{array}$ & XP_002946862/[21] & 85.2\% identity in 392 aa overlap & EDP06114/[22] & Blue and red light/[10] \\
\hline$A C D A$ & $\begin{array}{l}\text { Guanylyl and adenylate cyclase family } \\
\text { member/cAMP or CGMP production }\end{array}$ & ABM47321/[37] & 63.6\% identity in 154 aa overlap & XP_001702503/[22] & -——————-———— \\
\hline$C A$ & $\begin{array}{l}\text { Carbonic anhydrase/key enzyme } \\
\text { involves in involved in carbon } \\
\text { metabolism }\end{array}$ & XP_002951242/[21] & $50.8 \%$ identity in 374 aa overlap & BAA14232/[38] & White, blue and red light/[36,39] \\
\hline GLN1 & $\begin{array}{l}\text { Glutamine synthetase/key enzyme in } \\
\text { nitrogen metabolism }\end{array}$ & XP_002956198/[21] & $92.1 \%$ identity in 382 aa overlap & U46207/[40] & White, blue and red light/[10,40] \\
\hline FBP & $\begin{array}{l}\text { Fructose-1,6-bisphosphatase/key } \\
\text { enzymes involved in gluconeogenesis } \\
\text { and the Calvin cycle }\end{array}$ & XP_002948170 [21] & $88 \%$ identity in 415 aa overlap & XP_001690872/[22] & White light/[36] \\
\hline$R P E$ & $\begin{array}{l}\text { Ribulose phosphate-3-epimerase/key } \\
\text { enzymes involved in the Calvin cycle }\end{array}$ & $\begin{array}{l}\text { Photozyme ID: } \\
\text { Vocar20000806m.g/[21] }\end{array}$ & $90.2 \%$ identity in 264 aa overlap & XP_001691071/[22] & White light/[36] \\
\hline
\end{tabular}




\section{Light treatments}

To analyze cell-type specific light-mediated gene expression, the isolated reproductive and somatic cells were incubated for 26 hours in the dark before exposure to the test light of specific wavelengths for 1 hour (Additional file 1: Figure S1B). Light treatments were performed using LEDs of specific wavelengths with following equipment and settings: for blue light, Luxeon Rebel High Power Blue LED (Philips Lumileds), peak at $470 \mathrm{~nm}$ (with a typical spectral half-width of $20 \mathrm{~nm}$ ) and a photon fluence rate of $15 \mu \mathrm{mol}$ photons $\mathrm{m}^{-2} \mathrm{~s}^{-1}$; for red light, Luxeon Rebel High Power Deep Red LED (Philips Lumileds), peak at $655 \mathrm{~nm}$ (with a typical spectral halfwidth of $20 \mathrm{~nm}$ ) and a photon fluence rate of $15 \mu \mathrm{mol}$ photons $\mathrm{m}^{-2} \mathrm{~s}^{-1}$; for far-red light, High Efficacy Far Red LED (LED Engin), peak at $735 \mathrm{~nm}$ (with a typical spectral half-width of $25 \mathrm{~nm}$ ) and a photon fluence rate of $15 \mu \mathrm{mol}$ photons $\mathrm{m}^{-2} \mathrm{~s}^{-1}$ (Additional file 2: Figure S2). The light fluence rates were measured using a LI-250A light meter (Li-COR) and a red light meter (Model 9.6 Visible Red Light Meter, Solartech inc.).

\section{RNA isolation}

Total RNA was extracted from all samples using TRI Reagent (Sigma-Aldrich, St. Louis, MO) as described previously [19]. The extracted RNA was dissolved in RNase-free water and stored at $-70^{\circ} \mathrm{C}$. The integrity and size distribution of total RNA was checked by denaturing agarose-formaldehyde gel electrophoresis. The quantity and quality of extracted RNA were determined spectrophotometrically using an Ultrospec 2100 proUV/ Visible Spectrophotometer (GE Healthcare) at 260 and $280 \mathrm{~nm}$.

\section{Quantitative one-step real-time RT-PCR and data analysis}

Primers were designed to amplify cDNA fragments with 109 to $144 \mathrm{bp}$ in length (Additional file 3: Table S1). $1 \mu \mathrm{g}$ total RNA from each cell type (dark-adapted and after light treatments) was treated with 5 units DNaseI (Promega, Madison, WI) in DNase-I buffer $(20 \mathrm{mM}$ Tris, $\mathrm{pH} \mathrm{8.4,} 2 \mathrm{mM} \mathrm{MgCl}$, $50 \mathrm{mM} \mathrm{KCl}$ ) in a total volume of $10 \mu \mathrm{l}$ at $37^{\circ} \mathrm{C}$ for $10 \mathrm{~min}$ to remove contaminating DNA within the RNA preparation. The reaction was stopped by the addition of $1 \mu \mathrm{l} 25 \mathrm{mM}$ EDTA and incubation at $65^{\circ} \mathrm{C}$ for $10 \mathrm{~min}$. The RNA concentration was measured before and after DNAse-I treatment to ensure that the same RNA amount from different cell types were used in all reactions. The real-time RT-PCR was performed on a CFX96TM real-time PCR detection system (Bio-Rad) using the SensiFAST SYBR One-Step Kit (Bioline). All reactions contained 300 ng DNase-Itreated template RNA in a total volume of $20 \mu \mathrm{l}$. The reactions were incubated for $30 \mathrm{~min}$ at $50^{\circ} \mathrm{C}$ for cDNA synthesis followed by $2 \mathrm{~min}$ incubation at $95^{\circ} \mathrm{C}$ for initial Tag polymerase activation. The reactions were then subjected to 40 cycles of amplification, which consisted of a denaturing step at $95^{\circ} \mathrm{C}$ for $5 \mathrm{~s}$, an annealing step at $57^{\circ} \mathrm{C}$ for $10 \mathrm{~s}$ and an extension step at $72^{\circ} \mathrm{C}$ for $5 \mathrm{~s}$. All real-time RT-PCR experiments were carried out in triplicate from two different biological samples together with controls lacking RT or template to detect potential DNA contaminations. The relative expression level has been calculated using the $2^{-\Delta \Delta C t}$ as described previously $[37,43]$. RACK 1 , which has previously been used for normalization of light-dependent gene expression in the closely related algae Chlamydomonas reinhardtii $[10,11]$ and shows constitutive expression in both reproductive and somatic cells, was used for normalization of cell type specific light-mediated gene expression data.

\section{Results}

\section{Reproductive and somatic cells accumulate different} photoreceptors

The study of Volvox photoreceptors was almost always accompanied by questions regarding their cell-type specific functions. This multicellular green alga makes use of no less than 13 photoreceptors, i.e., seven rhodopsin-like photoreceptors (VR1, VChR1, VChR2, VcHKR1, VcHKR2, VcHKR3 and $V c H K R 4$ ), one UV-B photoreceptor (VcUVR8), four crypochromes (VcCRYa, VcCRYp, VcCRYd1 and $V c C R Y d 2$ ) and one phototropin (VcPhot) (Figure 1). In addition to the previous studies which showed that VR1 and channelrhodopsins are highly expressed in the reproductive and somatic cells, respectively $[19,20]$, recent investigations revealed that most photoreceptors are expressed in a cell-type specific manner [6,16] (Figure 1). These observations raise the question about the existence of different cell-type specific light signaling pathways in Volvox. To address this issue, we analyzed the cell-type specific change in the transcript accumulation of a set of genes which show light-induced changes in gene expression and are parts of downstream light signaling pathways [10,11,23,25,33,35,36,39]. For this purpose, the reproductive and somatic cells were separated three hours before initiation of cleavage division, followed by $26 \mathrm{~h}$ of incubation in the dark before exposure to blue, red or far-red light (Additional file 1: Figure S1A-B). However, because the cell-type specific transcript level of photoreceptors depends on the developmental stages, we analyzed their transcript levels right after separation of cell types, i.e. three hours before initiation of cleavage division, and at the end of dark incubation step (Additional file 1: Figure S1A-B). The results were in accordance with the previously reported data $[6,16,19,20]$ and showed the same localization of cellular expression for Volvox photoreceptors (Additional file 4: Figure S3 and Additional file 5: Figure S4, Figure 1). 
Volvox genes encoding components of light-harvesting system, carotenoid and chlorophyll biosynthesis, circadian clock, cell cycle and diverse metabolic pathways

In order to examine whether distinct cell-type specific light signaling pathways are exist in Volvox, the impact of light quality on the expression of a variety of genes encoding components of light-harvesting system, carotenoid and chlorophyll biosynthesis, circadian clock, cell cycle and diverse metabolic pathways was investigated. Because of the absence of any report studying lightmediated gene expression in Volvox, candidate genes were selected based on available observations from other algal systems such as Chlamydomonas and Phaeodactylum tricornutum $[10,11,26,33,35,36]$. The genes encoding components involved in light-harvesting system and chlorophyll biosynthesis include chloropyll a-b binding protein of LHCII type I (LHCBM6), a distant relative of light-harvesting chloropyll a-b protein (LHL4), magnesium chelatase subunit $\mathrm{D}(C H L D)$, glutamate-1-semialdehyde 2,1-aminomutase $(G S A)$, protochlorophyllide reductase $(P O R)$, delta-aminolevulinic acid dehydratase $(A L A D)$, oxygen evolving enhancer protein $1(O E E)$, disulfide isomerase RB60 (RB60) and RNA-binding protein RB38 (RB38) (Table 1). Two genes encoding enzymes of carotenoid biosynthesis pathway, i.e., phytoene desaturase (PDS) and phytoene synthase $(P S Y)$, that have been shown to be controlled by light $[10,11,35,36]$ were also selected. Additional genes encoding clock and cell cycle relevant components including $\mathrm{C} 1$ and $\mathrm{C} 3$ subunits of the circadian RNA-binding protein CHLAMY1 (CRB1 and CRB3) and a plant specific cyclin dependent kinase (CDKB1) were also analyzed (Table 1). Furthermore, genes encoding proteins involved in nitrogen metabolism (GLN1), carbon metabolisms ( $C A$ and $F B P$ ), pentose phosphate pathway $(P R E)$ and a guanylyl and adenylate cyclase family member (Table 1) have been added to this study. None of these genes had been studied before in Volvox concerning blue, red and far-red light-dependent regulation.

\section{Cell-type specific changes in transcript accumulation of genes encoding photosynthetic related/associated components in response to blue and red light}

In plants including algae, red and blue light have been shown to regulate the expression of photosynthetic associated genes $[25,44,45]$. To examine the effect of blue and red light on cell-type specific transcript accumulation of genes encode components of photosynthetic apparatus and related regulatory elements in Volvox, the reproductive and somatic cells were exposed to the monochromic blue $(470 \mathrm{~nm})$ and red $(655 \mathrm{~nm})$ light of equal photon fluence rate of 15 photons $\mathrm{m}^{-2} \mathrm{~s}^{-1}$ for $1 \mathrm{~h}$ (Additional file 1: Figure S1). As shown in Figure 2, the transcript levels of LHL4 and CHLD increased in response to blue light in both cell types (Figure 2A), while red light led to a marked increase in LHL4 transcript ( 11-fold) only in the somatic cells (Figure 2B). Following exposure of cell types to the blue light, the transcript of LHCBM6 increased in the somatic cells, but remained unchanged in the reproductive cells (Figure 2A). In contrast, slightly elevated transcript level of LHCBM6 was only observed in the reproductive cells in response to red light (Figure 2B). Furthermore, the level of $P O R$ transcript increased in response to the blue light in the somatic cells and, remarkably, decreased in those cells after exposure to the red light. However, only red light could elicit elevated expression of POR transcript in the reproductive cells (Figure 2A-B). Moreover, the transcript level of $O E E$ increased in response to the red light in the reproductive cells, whereas blue light led to decrease its level in these cells. The detected changes in the transcript level of $O E E$ in the somatic cells seem to be not statistically significant. The transcript of $R B 60$ increased in the somatic (remarkably) and reproductive (moderately) cells following blue light treatment, while red light led to elevated transcript level only in the reproductive cells (Figure 2A-B). These results show that blue and red light regulate the expression of genes encoding photosynthetic relevant components in both cell types in different ways, suggesting that cell-type specific light-induced signal transduction pathways underlying light-induced changes of photosynthetic related transcripts.

Blue and red light-induced changes in transcript accumulation of genes encoding carotenoid biosynthesis, cell cycle and clock relevant components in the reproductive and somatic cells

In the closely related alga Chlamydomonas, expression of two genes involved in carotenoids biosynthesis pathway, PDS and PSY, is affected by blue and red light $[10,11,35]$. In the multicellular Volvox, the transcript of PDS accumulated in each cell type in response to different light quality. Whereas blue light led to increase the transcript level of PDS in the somatic cells, red light induced accumulation of this transcript in the reproductive cells (Figure 3A-B). Unlike PDS, PSY transcript increased in both cell types after blue light irradiation. Red light, however, induced accumulation of PSY transcript only in the reproductive cells (Figure 3A-B). We also analyzed the effect of blue and red light on the transcript levels of two subunits of the circadian RNAbinding protein CHLAMY1, i.e., CRB1 and CRB2, which are shown to be associated with circadian clock in green algae [46]. A marked increase in transcript level of CRB3 ( 20-fold) was observed in the somatic cells after exposure to blue light (Figure 3A). CRB1 also exhibited a relatively high transcript accumulation in these cells following blue light exposure (Figure 3A). In 


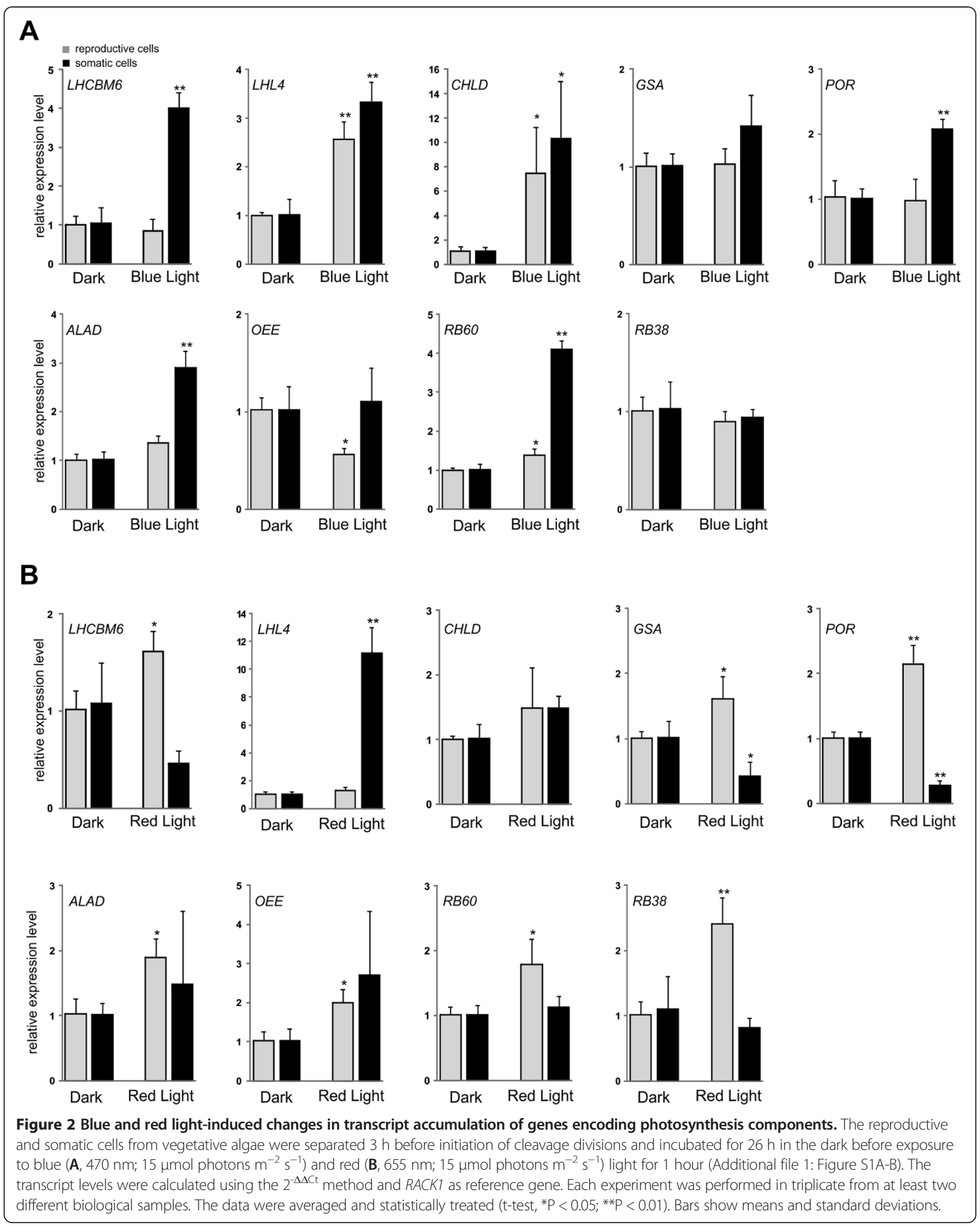




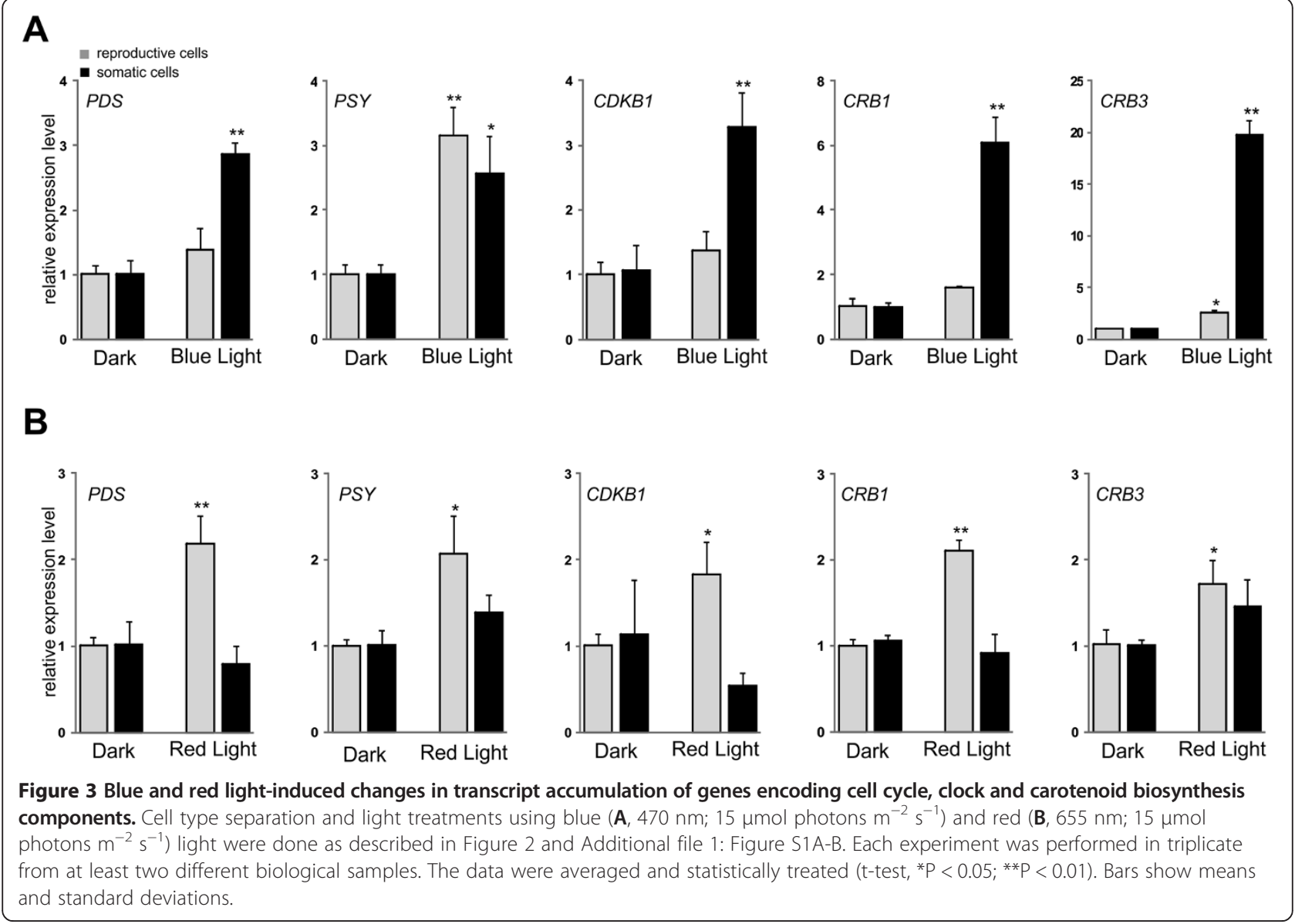

the reproductive cells, however, the transcript level of $C R B 1$ and $C R B 3$ were increased moderately in response to blue light. Remarkably, no significant changes in transcript level of these genes have been observed when the somatic cells were exposed to red light (Figure 3B). But in contrast, red light led to modest change in the transcript level of $C B R 1$ and $C R B 3$ in the reproductive cells (Figure 3A-B).

Recently, it was shown that the transcript level of $C D K B 1$, a plant specific cyclin-dependent kinase which is involved in the regulation of the cell cycle $[47,48]$, gradually increases following exposure of dark-adapted Chlamydomonas cells to red light. However, only modest changes in transcript abundance were observed after irradiation with blue light [10]. In Volvox, blue light elevated the transcript level of $C D K B 1$ only in the somatic cells (Figure 3A). Moreover, a small elevation in the transcript level of $C D K B 1$ in the reproductive cells was observed following exposure to red light, while no significant change has been observed in the somatic cells (Figure 3B). These results indicated that blue light induces transcript accumulation of the genes involved in circadian clock and cell cycle in the somatic cells, whereas no blue light-induced changes were observed in the reproductive cells.

\section{Blue and red light induced modulation of $A C D A$ and $C A$ transcript abundance}

Class III guanylyl and adenylyl cyclases represent one of the largest known protein families in the genome of Chlamydomonas and Volvox [21,22]. Although these cyclases are not identified so far in plants, they catalyze the synthesis of cGMP and cAMP, which serve as second messengers in a variety of signaling processes, in animals, fungi and prokaryotes [49,50]. A member of the guanylyl and adenylate cyclase family, i.e., $A C D A$, which has been previously shown to be more expressed in the somatic cells than in reproductive ones [37], was analyzed here. In the somatic cells, blue light led to induce expression of $A C D A$, however, the level was remarkably reduced $(\sim 5$-fold $)$ following exposure of the cells to the red light (Figure 4A-B). Both blue and red light caused also decreased level of $C A$ transcript encoding a zinc-containing carbonic anhydrase in the somatic cells. In contrast, the level of $A C D A$ and $C A$ transcripts was increased in response to the red light in the reproductive cells (Figure 4A-B). 


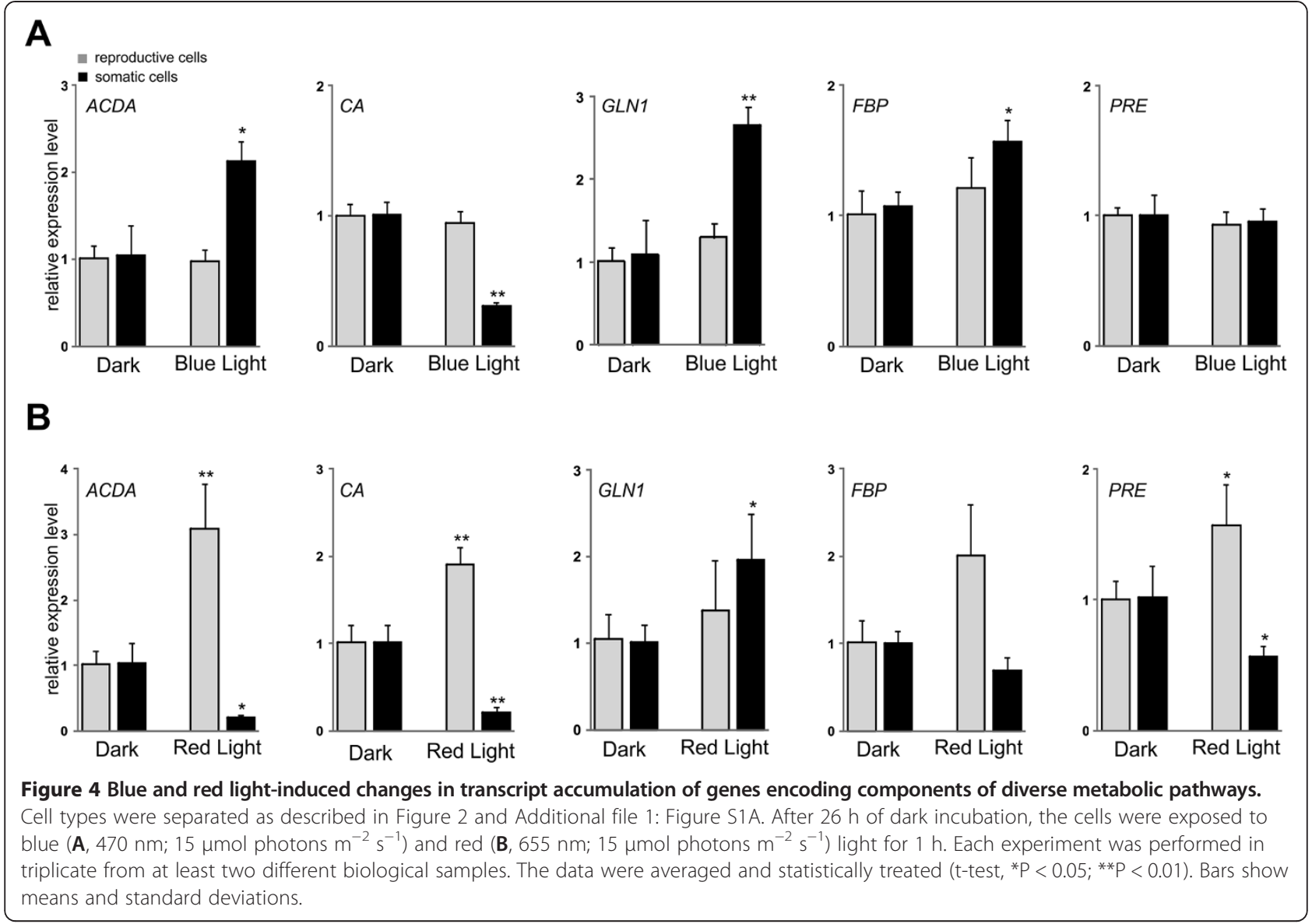

Far-red light causes only modest changes in the levels of transcripts from $L H L 4, P S Y$ and $A C D A$

Plants make use of red/far-red light-absorbing phytochrome photoreceptors to measure the ratio of red/ far-red light that mediate physiological responses by regulating gene expression [51,52]. Although phytochromes also have been found in charophyta, a division of green algae that includes the closest relatives of the embryophyte plants [53,54]; no phytochrome genes could be identified in the genomes of volvocine algae Volvox and Chlamydomonas, even though red- and far-red-regulated gene expression has been observed $[6,10,11,33]$. As shown in Additional file 6: Figure S5, we could only detect the modest effect of far-red light (735 nm, photon fluence rate of 15 photons $\mathrm{m}^{-2} \mathrm{~s}^{-1}$ ) on the transcript levels of LHL4, PSY and ACDA. Whereas the transcript level of $L H L 4$ and PSY increased in the somatic cells after far-red light treatments, a reduced level of $A C D A$ transcript was observed in both cell types (Additional file 6: Figure S5). These results indicate that the changes in transcript level of genes analyzed in this study are more sensitive to the blue and red light than far-red light. On the other hand, this observation could be interpreted as small support for the existence of a putative far-red-light signaling pathways in the volvocine algae including Volvox.

\section{Discussion}

In this study, cell-type specific changes of transcript accumulation of genes associated with various metabolic and cellular pathways in response to the light of different wavelengths were analyzed in Volvox. With respect to the cell-type specific photoreceptors, it is very likely that this multicellular alga uses different cell-type specific light signaling pathways to regulate gene expression in a cell-type specific fashion. The results presented here provide an insight into the cell-types specific changes of transcript accumulation which is required to utilize environmental clues such as light towards adequate adaptation of light-affected cellular and developmental processes in each cell type.

Blue and red light induce quantitative difference of transcript accumulation in both cell types

Plants including algae use various kinds of photoreceptors to sense changes in environmental light and to mediate diverse physiological and developmental processes by photoreceptor-mediated orchestrating of gene 
expression $[52,55]$. These light-sensitive proteins allow efficient reprogramming of transcriptome by light-induced activation of transcription factors or regulation of lightinduced splicing of target genes [56,57]. Moreover, tissue or developmentally regulated expression of photoreceptors and/or associated signaling components triggers changes in transcript level of distinct target genes in different organs [58-60]. Considering the fact that the most Volvox photoreceptors are expressed in a cell-type specific manner (Figure 1), the main issue to be dealt with is whether this multicellular alga makes use of different distinct light signaling pathways to regulate gene expression in its two entirely different cell types, especially in response to the environmental light. The data presented here show that blue and red light induce cell-type specific changes in the level of transcripts from the most but not all analyzed genes. The transcript of four genes belonging to various functional categories, i.e., POR, PDS, $C R B 1$ and $A C D A$, accumulated in the reproductive and somatic cells in response to different light qualities, i.e., red and blue light, respectively (Figure 5). Our data also show that the transcript accumulation in the somatic cells is more sensitive to blue light (14 genes), while red light led to accumulate more transcripts (15 genes) in the reproductive cells (Figure 5). Only GLN1 and LHL4 showed increase in transcript levels after red light treatment in the somatic cells. In the closely related alga Chlamydomonas, blue light was shown to be more effective for inducing LHL4 gene expression than red or far-red light [25]. However, although LHL4 transcript accumulated in both Volvox cell types in response to blue light (Figure 2A), red (a marked increase) and far-red (a modest increase) light could elicit elevated expression only in the somatic cells (Figure 2B, Figure 5 and Additional file 6: Figure S5).

In higher plants, a large number of genes are obviously repressed by blue, red and far-red light $[9,61,62]$. Among analyzed genes in this study, only five transcripts were found to be repressed (with a ratio of 0.31 -fold or less)

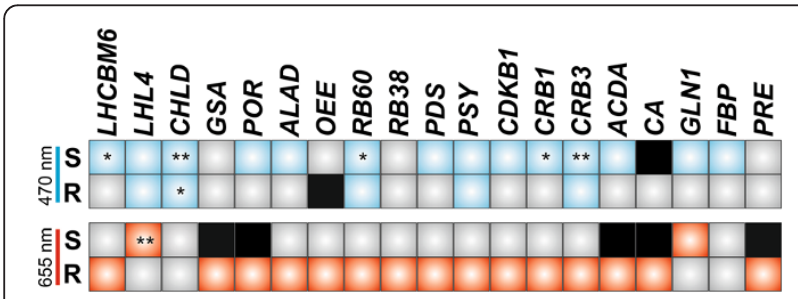

Figure 5 Cell-type specific light-mediated changes of transcript level. Enhanced gene expression by blue $(470 \mathrm{~nm})$ and red $(655 \mathrm{~nm})$ light in the somatic (S) and reproductive (R) cells is highlighted by blue and red, respectively, while repressed expression is shown by black. Grey shows no change in transcript level under given light-treatment. * and ** indicate more than four- and eight-fold increase in transcript level, respectively. in the somatic cells after $1 \mathrm{~h}$ of blue and/or red light irradiation; the carbonic anhydrase gene $C A$ was down regulated following both blue and red light treatments (Figure 4A-B), while $A C D A, G S A, P R E$ and $P O R$ were decreased only in response to red light (Figure $2 \mathrm{~B}$ and Figure 4B). On the other hand, in the reproductive cells, the transcripts of all these five genes were increased after red light treatment (Figure 5). This indicates that the same light quality causes induction or repression of genes in a cell type-dependent fashion, suggesting that different transcription factors could be involved in downstream red-light-signaling pathway in the two cell types.

\section{Cell-type specific light signaling pathways behind cellular differentiation}

During evolution, the development of complex eukaryotic organisms such as Volvox is generated through selective expression of specific fraction of the same genome in different cell types in response to developmental and environmental cues $[59,63]$. The two cell types of this multicellular alga represent differential expression pattern of genes from various functional classes $[37,64,65]$. However, little is known regarding cell-type specific changes of gene expression in response to environmental cues including light, which is one of most important environmental signals for controlling growth and development in plants including algae $[1,5,6,66,67]$. In plants, for example, blue and red/far-red light are of great importance for the optimization of cellular and developmental processes such as photosynthesis by shade avoidance response and chloroplast positioning [44,68-70]. Moreover, it is generally assumed that photoreceptors induce light-modulated gene expression to direct appropriate growth and developmental responses [44,62,71]. Comparison of the gene expression profiles of the reproductive and somatic cells reported here revealed that distinct cell-type specific light signaling pathways underlying gene expression modulate appropriate transcript regulation in response to light. Thus, different qualities of light appear to trigger distinct celltype specific changes in transcript level (Figure 5). In particular, blue light increased the transcript level of two photosynthetic relevant components, i.e., LHCBM6 and $P O R$, only in the somatic cells, while those levels were elevated in the reproductive cells by red light (Figure 2A-B). On the other hand, a marked increase in LHL4 transcript was observed in the somatic cells exposure to red light, while no change was detected in the reproductive cells exposure to the same light quality (Figure 2B). In $\mathrm{Vol}$ vox, regulation of photosynthesis is believed to be the key difference between both cell types. Whereas nuclear genes encode important chloroplast proteins are expressed abundantly in the reproductive cells, repression of their 
transcription in the somatic cells blocks reproductive activity by preventing cell growth [65,72,73]. In Chlamydomonas, expression of genes associated with photosynthetic function is affected by blue and red light [23,25,33]. Light signaling mediated by phototropin and cryptochrome was shown to be implicated in the induction of gene expression $[10,11]$. The observed cell-type specific changes in transcript accumulation of genes associated with photosynthesis in response to light can be traced back to the Volvox photoreceptors, which are mostly expressed in a cell-type specific fashion.

In addition, we observed that the transcript of $C R B 1$ and $C R B 3$ genes encoding $\mathrm{C} 1$ and $\mathrm{C} 3$ subunits of RNAbinding protein CHLAMY1, respectively, increased in response to blue light in the somatic cells, but not in the reproductive cells. It has previously been reported that the binding activity of CHLAMY1 changes in a circadian manner [74]. Interaction between CHLAMY1 and these subunits is necessary for RNA-binding activity [75]. Moreover, changes in the level of $\mathrm{C} 1$ and $\mathrm{C} 3$ affect circadian rhythms in Chlamydomonas [46]. A marked increase in the transcript of $C R B 3$ in the somatic cells after $1 \mathrm{~h}$ exposure to blue light ( $\sim 20$-fold) is also consistent with recent report by Beel et al. [10] that showed an $\sim 15$-fold increase in the C3 transcript after the cells were exposed to $30 \mathrm{~min}$ of blue light [10]. However, in contrast, we did not observed any effect of red and farred light on the transcript level of $C R B 3$ and $C R B 1$ in the somatic cells, indicating that blue light is more effective for inducing these clock-relevant components. Therefore, based on these observations in conjunction with a previous study by Iliev et al. [46], it is logical to suggest that blue light affect circadian rhythms in a cell-type specific manner. This conclusion is consistent with a recently reported study about cell-type specific circadian rhythms in Arabidopsis, which demonstrated that stomatal guard cells have a different period from surrounding epidermal and mesophyll leaf cells [76].

\section{Biological significance of cell-type specific light signaling pathways}

In nature, the Volvox populations swim downward to reach cool and dark regions at twilight and then swim back to the euphotic zone at dawn [77]. Because of the wavelength dependent penetration of the light in water $[78,79]$, changes in detected wavelengths or spectral composition of light could be detected as an environmental signal cue to swim down- or upward at twilight and dawn, respectively, and to regulate developmental and physiological processes for day and night adaptation. Obviously, Volvox makes use of a variety of photoreceptors to sense changes in light properties (direction, quality and intensity). Diverse photoreceptors have been shown to be localized within the eyespot of volvocine algae $[19,80,81]$, indicating that eyespot and associated structures [5] serve as general sensory organelles to modulate photobehavior, i.e., phototaxis and photophobic responses, and potentially other developmental or adaptive responses. Thus, the eyespot apparatus is required for accurate light-monitoring and light-dependent movement responses to optimize the photosynthetic activities or to avoid photodamages. In Volvox, eyespots are exclusively restricted to the somatic cells, in which the most photoreceptor genes are expressed. On other hand, only VR1 is highly expressed in the reproductive cells (Figure 1). Cell-type specific distribution of photoreceptors enables both cell types to optimize cellular and developmental processes differentially in response to environmental light. In addition, light also serves as a time cue that daily resets the circadian rhythms. The light quality, e.g., amount and spectral composition, changes during twilight. For example, twilight is primarily characterized by relative enrichment of the shorter wavelengths $(<500 \mathrm{~nm})$ compared to the mid-long wavelengths $(500-650 \mathrm{~nm})$ [82]. The ability to sense changes in the light quality (for example, detection of blue light at dawn) triggers signaling pathways towards adjusting cellular processes. However, the marked changes in transcripts of clock relevant components $C R B 1$ and $C R B 3$ in the somatic cells in response to only blue light indicate that each cell type has its own genetically predefined circadian rhythm. Moreover, depends on environmental light, physiological and metabolic activities have been shown to be fine-tuned in green algae (reviewed in [1]). In Chlamydomonas, it was shown that the activity of carbonic anhydrase $(C A)$ is under blue and red light control. The authors could show that photosynthesis is required for regulation of $C A$ and, in addition, a blue light stimulated mechanism is also involved in $C A$ transcript regulation [39]. Moreover, inhibition studies and mutant analysis have shown that $C A$ is important to the function of photosynthesis in Chlamydomonas [83]. In Volvox, photosynthetic activities seem to be differentially regulated, in the light of morphological and physiological differences between two cell types. Illumination of reproductive cells with red light (which is needed for the photosynthesis-dependent process) led to accumulation of $C A$ transcript, while both blue and red light led to reduce its transcript level in the somatic cells (Figure 4). In other words, depending on cell type, light signals could increase or decrease photosynthetic activities. Therefore, it is to assume that distinct light signaling pathways have been evolved to modulate differential regulation of photosynthetic related components in response to environmental light that ensure development and function of specific types of cells.

\section{Conclusions}

The results presented here demonstrate that the multicellular green alga Volvox uses different cell-type specific 
light signaling pathways to modulate gene expression in a cell-type specific manner. This sophisticated gene expression system has been potentially assured through cell-type specific expression of photoreceptors and allows differential regulation of genes involved in various cellular and metabolic pathways in response to environmental light.

\section{Availability of supporting data}

The data sets supporting the results of this article are included within the article and its additional files.

\section{Additional files}

Additional file 1: Figure S1. Light treatments of Volvox cell types.

Additional file 2: Figure S2. Spectral distribution and optical

characteristics of used LEDs.

Additional file 3: Table S1. Primer sequences and amplicon characteristics.

Additional file 4: Figure S3. Cell-type specific transcript analysis of photoreceptor genes $3 \mathrm{~h}$ before initiation of cleavage division.

Additional file 5: Figure S4. Cell-type specific transcript analysis of photoreceptor genes after dark incubation -just before exposure to the test light.

Additional file 6: Figure S5. Effect of far-red light on cell-type specific transcript accumulation.

\section{Competing interests}

The author declares that he has no competing interests.

\section{Acknowledgements}

I thank Noriko Ueki (Department of Biological Sciences, Chuo University) for reading of the manuscript and helpful suggestions. I also would like to gratefully thank Kordula Puls for technical assistance and Achim Müller for constructing LEDs and electronic devices required for light-dependent gene expression analysis in this study. I also wish to thank Prof. Dr. Armin Hallmann for the possibility to conduct all experiments in his lab. This work was funded by a grant (KI 1779/1-1) from the German Research Foundation (DFG) to AK.

Received: 6 March 2014 Accepted: 3 September 2014

Published: 6 September 2014

\section{References}

1. Grossman AR, Lohr M, Im CS: Chlamydomonas reinhardtii in the landscape of pigments. Annu Rev Genet 2004, 38:119-173.

2. Kirk MM, Kirk DL: Translational regulation of protein-synthesis, in response to light, at a critical stage of Volvox development. Cell 1985, 41(2):419-428.

3. Huang KY, Beck CF: Photoropin is the blue-light receptor that controls multiple steps in the sexual life cycle of the green alga Chlamydomonas reinhardtii. Proc Natl Acad Sci U S A 2003, 100(10):6269-6274.

4. Oldenhof $H$, Zachleder $V$, van den Ende H: Blue light delays commitment to cell division in Chlamydomonas reinhardtii. Plant Biol (Stuttg) 2004, 6(6):689-695.

5. Foster KW, Smyth RD: Light antennas in phototactic algae. Microbiol Rev 1980, 44(4):572-630

6. Kianianmomeni A, Hallmann A: Algal photoreceptors: in vivo functions and potential applications. Planta 2014, 239(1):1-26

7. Hegemann P: Algal sensory photoreceptors. Annu Rev Plant Biol 2008, 59:167-189.

8. Liu B, Zuo ZC, Liu HT, Liu XM, Lin CT: Arabidopsis cryptochrome 1 interacts with SPA1 to suppress COP1 activity in response to blue light. Genes Dev 2011, 25(10):1029-1034.

9. Jiao Y, Yang H, Ma L, Sun N, Yu H, Liu T, Gao Y, Gu H, Chen Z, Wada M, Gerstein M, Zhao H, Qu LJ, Deng XW: A genome-wide analysis of blue- light regulation of Arabidopsis transcription factor gene expression during seedling development. Plant Physiol 2003, 133(4):1480-1493.

10. Beel B, Prager K, Spexard M, Sasso S, Weiss D, Muller N, Heinnickel M, Dewez D, Ikoma D, Grossman AR, Kottke T, Mittag M: A flavin binding cryptochrome photoreceptor responds to both blue and red light in Chlamydomonas reinhardtii. Plant Cell 2012, 24(7):2992-3008.

11. Im CS, Eberhard S, Huang K, Beck CF, Grossman AR: Phototropin involvement in the expression of genes encoding chlorophyll and carotenoid biosynthesis enzymes and LHC apoproteins in Chlamydomonas reinhardtii. Plant J 2006, 48(1):1-16.

12. Sineshchekov OA, Jung KH, Spudich JL: Two rhodopsins mediate phototaxis to low- and high-intensity light in Chlamydomonas reinhardtii. Proc Natl Acad Sci U S A 2002, 99(13):8689-8694.

13. Deininger $W$, Kroger $P$, Hegemann $U$, Lottspeich F, Hegemann $P$ : Chlamyrhodopsin represents a new type of sensory photoreceptor. EMBO J 1995, 14(23):5849-5858.

14. Trippens J, Greiner A, Schellwat J, Neukam M, Rottmann T, Lu Y, Kateriya S, Hegemann P, Kreimer G: Phototropin influence on eyespot development and regulation of phototactic behavior in Chlamydomonas reinhardtii. Plant Cell 2012, 24:4687-4702.

15. Kirk DL: A twelve-step program for evolving multicellularity and a division of labor. Bioessays 2005, 27(3):299-310.

16. Kianianmomeni A, Hallmann A: Transcriptional analysis of Volvox photoreceptors suggests the existence of different cell-type specific light signaling pathways. Curr Genet 2014. doi:10.1007/s00294-014-0440-3.

17. Kirk D: Volvox: molecular-genetic origins of multicellularity and cellular differentiation. Cambridge, UK: Cambridge University Press; 1998.

18. Hallmann A: Extracellular matrix and sex-inducing pheromone in Volvox. Int Rev Cytol 2003, 227:131-182.

19. Kianianmomeni A, Stehfest K, Nematollahi G, Hegemann P, Hallmann A: Channelrhodopsins of Volvox carteri are photochromic proteins that are specifically expressed in somatic cells under control of light, temperature, and the sex inducer. Plant Physiol 2009, 151(1):347-366.

20. Ebnet E, Fischer M, Deininger W, Hegemann P: Volvoxrhodopsin, a lightregulated sensory photoreceptor of the spheroidal green alga Volvox carteri. Plant Cell 1999, 11(8):1473-1484.

21. Prochnik SE, Umen J, Nedelcu AM, Hallmann A, Miller SM, Nishii I, Ferris $P$, Kuo A, Mitros T, Fritz-Laylin LK, Hellsten U, Chapman J, Simakov O, Rensing SA, Terry A, Pangilinan J, Kapitonov V, Jurka J, Salamov A, Shapiro H, Schmutz J, Grimwood J, Lindquist E, Lucas S, Grigoriev IV, Schmitt R, Kirk D, Rokhsar DS: Genomic analysis of organismal complexity in the multicellular green alga Volvox carteri. Science 2010, 329(5988):223-226.

22. Merchant SS, Prochnik SE, Vallon O, Harris EH, Karpowicz SJ, Witman GB, Terry A, Salamov A, Fritz-Laylin LK, Marechal-Drouard L, Marshall WF, Qu LH, Nelson DR, Sanderfoot AA, Spalding MH, Kapitonov W, Ren Q, Ferris P, Lindquist E, Shapiro H, Lucas SM, Grimwood J, Schmutz J, Cardol P, Cerutti H, Chanfreau G, Chen CL, Cognat V, Croft MT, Dent R, et al: The Chlamydomonas genome reveals the evolution of key animal and plant functions. Science 2007, 318(5848):245-250.

23. Johanningmeier $\mathrm{U}$, Howell SH: Regulation of light-harvesting chlorophyllbinding protein mRNA accumulation in Chlamydomonas reinhardi. Possible involvement of chlorophyll synthesis precursors. J Biol Chem 1984, 259(21):13541-13549.

24. Teramoto $H$, Itoh T, Ono TA: High-intensity-light-dependent and transient expression of new genes encoding distant relatives of light-harvesting chlorophyll-a/b proteins in Chlamydomonas reinhardtii. Plant Cell Physiol 2004, 45(9):1221-1232.

25. Teramoto H, Ishii A, Kimura Y, Hasegawa K, Nakazawa S, Nakamura T, Higashi S, Watanabe M, Ono TA: Action spectrum for expression of the high intensity light-inducible Lhc-like gene Lhl4 in the green alga Chlamydomonas reinhardtii. Plant Cell Physiol 2006, 47(3):419-425.

26. Vasileuskaya Z, Oster U, Beck CF: Involvement of tetrapyrroles in interorganellar signaling in plants and algae. Photosynth Res 2004, 82(3):289-299.

27. Matters $\mathrm{GL}$, Beale SI: Structure and light-regulated expression of the gsa gene encoding the chlorophyll biosynthetic enzyme, glutamate 1-semialdehyde aminotransferase, in Chlamydomonas reinhardtii. Plant Mol Biol 1994, 24(4):617-629.

28. Matters $\mathrm{GL}$, Beale SI: Blue-light-regulated expression of genes for two early steps of chlorophyll biosynthesis in Chlamydomonas reinhardtii. Plant Physiol 1995, 109(2):471-479. 
29. Li J, Timko MP: The pc-1 phenotype of Chlamydomonas reinhardtii results from a deletion mutation in the nuclear gene for NADPH: protochlorophyllide oxidoreductase. Plant Mol Biol 1996, 30(1):15-37.

30. Matters GL, Beale SI: Structure and expression of the Chlamydomonas reinhardtii alad gene encoding the chlorophyll biosynthetic enzyme, delta-aminolevulinic acid dehydratase (porphobilinogen synthase). Plant Mol Biol 1995, 27(3):607-617.

31. Mayfield SP, Schirmerrahire M, Frank G, Zuber H, Rochaix JD: Analysis of the genes of the OEE1 and OEE3 proteins of the photosystem II complex from Chlamydomonas reinhardtii. Plant Mol Biol 1989, 12(6):683-693.

32. Kim JM, Mayfield SP: Protein disulfide isomerase as a regulator of chloroplast translational activation. Science 1997, 278(5345):1954-1957.

33. Alizadeh D, Cohen A: Red light and calmodulin regulate the expression of the psbA binding protein genes in Chlamydomonas reinhardtii. Plant Cell Physiol 2010, 51(2):312-322

34. Barnes D, Cohen A, Bruick RK, Kantardjieff K, Fowler S, Efuet E, Mayfield SP: Identification and characterization of a novel RNA binding protein that associates with the $5^{\prime}$-untranslated region of the chloroplast psbA mRNA. Biochemistry 2004, 43(26):8541-8550.

35. Bohne $\mathrm{F}$, Linden $\mathrm{H}$ : Regulation of carotenoid biosynthesis genes in response to light in Chlamydomonas reinhardtii. Biochim Biophys Acta 2002, 1579(1):26-34.

36. Coesel S, Mangogna M, Ishikawa T, Heijde M, Rogato A, Finazzi G, Todo T, Bowler C, Falciatore A: Diatom PtCPF1 is a new cryptochrome/photolyase family member with DNA repair and transcription regulation activity. EMBO Rep 2009, 10(6):655-661.

37. Nematollahi G, Kianianmomeni A, Hallmann A: Quantitative analysis of cell-type specific gene expression in the green alga Volvox carteri. BMC Genomics 2006, 7:321.

38. Fukuzawa H, Fujiwara S, Tachiki A, Miyachi S: Nucleotide sequences of two genes $\mathrm{CAH} 1$ and $\mathrm{CAH} 2$ which encode carbonic anhydrase polypeptides in Chlamydomonas reinhardtii. Nucleic Acids Res 1990, 18(21):6441-6442.

39. Dionisio-Sese ML, Fukuzawa H, Miyachi S: Light-induced carbonic anhydrase expression in Chlamydomonas reinhardtii. Plant Physiol 1990, 94(3):1103-1110

40. Chen Q, Silflow CD: Isolation and characterization of glutamine synthetase genes in Chlamydomonas reinhardtii. Plant Physiol 1996, 112(3):987-996

41. Adams CR, Stamer KA, Miller JK, McNally JG, Kirk MM, Kirk DL: Patterns of organellar and nuclear inheritance among progeny of two geographically isolated strains of Volvox carteri. Curr Genet 1990, 18(2):141-153.

42. Provasoli L, Pintner IJ: Artificial Media for Fresh-Water Algae: Problems and Suggestions. In The Ecology of Algae, a Symposium Held at the Pymatuning Laboratory of Field Biology on June 18 and 19, 1959, (ed). Edited by Tryon CA, Hartman RT. Pittsburgh, PA: The Pymatuning Symposia in Ecology, Special Publication No 2, University of Pittsburgh; 1959:84-96.

43. Kianianmomeni A, Hallmann A: Validation of reference genes for quantitative gene expression studies in Volvox carteri using real-time RT-PCR. Mol Biol Rep 2013, 40:6691-6699.

44. Ma L, Li J, Qu L, Hager J, Chen Z, Zhao H, Deng XW: Light control of Arabidopsis development entails coordinated regulation of genome expression and cellular pathways. Plant Cell 2001, 13(12):2589-2607.

45. Hamazato F, Shinomura T, Hanzawa H, Chory J, Furuya M: Fluence and wavelength requirements for Arabidopsis $C A B$ gene induction by different phytochromes. Plant Physiol 1997, 115(4):1533-1540.

46. Iliev D, Voytsekh O, Schmidt EM, Fiedler M, Nykytenko A, Mittag M: A heteromeric RNA-binding protein is involved in maintaining acrophase and period of the circadian clock. Plant Physiol 2006, 142(2):797-806.

47. Cizkova M, Pichova A, Vitova M, Hlavova M, Hendrychova J, Umysova D, Galova E, Sevcovicova A, Zachleder V, Umen JG, Bisova K: CDKA and CDKB kinases from Chlamydomonas reinhardtii are able to complement cdc28 temperature-sensitive mutants of Saccharomyces cerevisiae. Protoplasma 2008, 232(3-4):183-191.

48. Bisova K, Krylov DM, Umen JG: Genome-wide annotation and expression profiling of cell cycle regulatory genes in Chlamydomonas reinhardtii. Plant Physiol 2005, 137(2):475-491.

49. Schaap P: Guanylyl cyclases across the tree of life. Front Biosci 2005, 10:1485-1498.

50. Shenroy AR, Visweswariah SS: Class III nucleotide cyclases in bacteria and archaebacteria: lineage-specific expansion of adenylyl cyclases and a dearth of guanylyl cyclases. FEBS Lett 2004, 561(1-3):11-21.
51. Franklin KA, Whitelam GC: Light-quality regulation of freezing tolerance in Arabidopsis thaliana. Nature Genet 2007, 39(11):1410-1413.

52. Nagatani A: Light-regulated nuclear localization of phytochromes. Curr Opin Plant Biol 2004, 7(6):708-711.

53. Winands A, Wagner G: Phytochrome of the green alga Mougeotia: cDNA sequence, autoregulation and phylogenetic position. Plant Mol Biol 1996, 32(4):589-597.

54. Kidd DG, Lagarias JC: Phytochrome from the green alga Mesotaenium caldariorum. J Biol Chem 1990, 265(12):7029-7035.

55. Casal JJ, Yanovsky MJ: Regulation of gene expression by light. Int J Dev Biol 2005, 49(5-6):501-511.

56. Wu HP, Su YS, Chen HC, Chen YR, Wu CC, Lin WD, Tu SL: Genome-wide analysis of light-regulated alternative splicing mediated by photoreceptors in Physcomitrella patens. Genome Biol 2014, 15(1):R10.

57. Jiao $Y$, Lau OS, Deng XW: Light-regulated transcriptional networks in higher plants. Nat Rev Genet 2007, 8(3):217-230.

58. Lopez-Juez E, Dillon E, Magyar Z, Khan S, Hazeldine S, de Jager SM, Murray JA, Beemster GT, Bogre L, Shanahan H: Distinct light-initiated gene expression and cell cycle programs in the shoot apex and cotyledons of Arabidopsis. Plant Cell 2008, 20(4):947-968

59. Ma L, Sun N, Liu X, Jiao Y, Zhao H, Deng XW: Organ-specific expression of Arabidopsis genome during development. Plant Physiol 2005, 138(1):80-91.

60. Kami C, Lorrain S, Hornitschek P, Fankhauser C: Light-regulated plant growth and development. Curr Top Dev Biol 2010, 91:29-66.

61. Molas ML, Kiss JZ, Correll MJ: Gene profiling of the red light signalling pathways in roots. J Exp Bot 2006, 57(12):3217-3229.

62. Tepperman JM, Zhu T, Chang HS, Wang X, Quail PH: Multiple transcriptionfactor genes are early targets of phytochrome A signaling. Proc Natl Acad Sci U S A 2001, 98(16):9437-9442.

63. Meyerowitz EM: Plants compared to animals: the broadest comparative study of development. Science 2002, 295(5559):1482-1485.

64. Tam LW, Kirk DL: Identification of cell-type-specific genes of Volvox carter and characterization of their expression during the asexual life cycle. Dev Biol 1991, 145(1):51-66

65. Meissner M, Stark K, Cresnar B, Kirk DL, Schmitt R: Volvox germline-specific genes that are putative targets of RegA repression encode chloroplast proteins. Curr Genet 1999, 36(6):363-370.

66. Deng XW, Quail PH: Signalling in light-controlled development. Semin Cell Dev Biol 1999, 10(2):121-129.

67. Neff MM, Fankhauser C, Chory J: Light: an indicator of time and place. Genes Dev 2000, 14(3):257-271.

68. Suetsugu N, Wada M: Chloroplast photorelocation movement mediated by phototropin family proteins in green plants. Biol Chem 2007, 388(9):927-935.

69. Franklin KA: Shade avoidance. New Phytologist 2008, 179(4):930-944

70. Hudson ME, Lisch DR, Quail PH: The FHY3 and FAR1 genes encode transposase-related proteins involved in regulation of gene expression by the phytochrome A-signaling pathway. Plant J 2003, 34(4):453-471.

71. Quail PH: Phytochrome photosensory signalling networks. Nat Rev Mol Cell Biol 2002, 3(2):85-93.

72. Duncan L, Nishii I, Howard A, Kirk D, Miller SM: Orthologs and paralogs of regA, a master cell-type regulatory gene in Volvox carteri. Curr Genet 2006, 50(1):61-72.

73. Kirk MM, Stark K, Miller SM, Muller W, Taillon BE, Gruber H, Schmitt R, Kirk DL: regA, a Volvox gene that plays a central role in germ-soma differentiation, encodes a novel regulatory protein. Development 1999 126(4):639-647.

74. Mittag M: Conserved circadian elements in phylogenetically diverse algae. Proc Natl Acad Sci U S A 1996, 93(25):14401-14404.

75. Zhao B, Schneid C, Iliev D, Schmidt EM, Wagner V, Wollnik F, Mittag M: The circadian RNA-binding protein CHLAMY 1 represents a novel type heteromer of RNA recognition motif and lysine homology domaincontaining subunits. Eukaryot Cell 2004, 3(3):815-825.

76. Yakir E, Hassidim M, Melamed-Book N, Hilman D, Kron I, Green RM: Cell autonomous and cell-type specific circadian rhythms in Arabidopsis. Plant J 2011, 68(3):520-531.

77. Sommer U, Gliwicz ZM: Long-range vertical migration of Volvox in tropical lake Cahora Bassa (Mozambique). Limnol Oceanogr 1986, 31(3):650-653

78. Moran MA, Miller WL: Resourceful heterotrophs make the most of light in the coastal ocean. Nat Rev Microbiol 2007, 5(10):792-800. 
79. Ragni M, D'Alcala MR: Light as an information carrier underwater. J Plankton Res 2004, 26(4):433-443.

80. Suzuki T, Yamasaki K, Fujita S, Oda K, Iseki M, Yoshida K, Watanabe M, Daiyasu H, Toh H, Asamizu E, Tabata S, Miura K, Fukuzawa H, Nakamura S, Takahashi T: Archaeal-type rhodopsins in Chlamydomonas: model structure and intracellular localization. Biochem Biophys Res Commun 2003, 301(3):711-717.

81. Luck M, Mathes T, Bruun S, Fudim R, Hagedorn R, Nguyen TM, Kateriya S, Kennis JT, Hildebrandt P, Hegemann P: A photochromic histidine kinase rhodopsin (HKR1) that is bimodally switched by UV and blue light. J Biol Chem 2012, 287:40083-40090.

82. Roenneberg T, Foster RG: Twilight times: light and the circadian system. Photochem Photobiol 1997, 66(5):549-561.

83. Moroney JV, Ma Y, Frey WD, Fusilier KA, Pham TT, Simms TA, DiMario RJ, Yang J, Mukherjee B: The carbonic anhydrase isoforms of Chlamydomonas reinhardtii: intracellular location, expression, and physiological roles. Photosynth Res 2011, 109(1-3):133-149.

doi:10.1186/1471-2164-15-764

Cite this article as: Kianianmomeni: Cell-type specific light-mediated transcript regulation in the multicellular alga Volvox carteri. BMC Genomics 2014 15:764.

\section{Submit your next manuscript to BioMed Central and take full advantage of:}

- Convenient online submission

- Thorough peer review

- No space constraints or color figure charges

- Immediate publication on acceptance

- Inclusion in PubMed, CAS, Scopus and Google Scholar

- Research which is freely available for redistribution 